\title{
Impact of aging on the clinical outcomes of Japanese patients with coronary artery disease after percutaneous coronary intervention
}

\author{
Hidehiro Kaneko $\cdot$ Junji Yajima $\cdot$ Yuji Oikawa $\cdot$ Shingo Tanaka $\cdot$ Daisuke Fukamachi $\cdot$ Shinya Suzuki \\ Koichi Sagara $\cdot$ Takayuki Otsuka $\cdot$ Shunsuke Matsuno $\cdot$ Ryuichi Funada $\cdot$ Hiroto Kano $\cdot$ \\ Tokuhisa Uejima $\cdot$ Akira Koike Kazuyuki Nagashima $\cdot$ Hajime Kirigaya $\cdot$ Hitoshi Sawada \\ Tadanori Aizawa $\cdot$ Takeshi Yamashita
}

Received: 20 August 2012/ Accepted: 8 March 2013/Published online: 4 April 2013

(C) The Author(s) 2013. This article is published with open access at Springerlink.com

\begin{abstract}
Japan has become an aging society, resulting in an increased prevalence of coronary artery disease. However, clinical outcomes of elderly Japanese patients after percutaneous coronary intervention (PCI) remain unclear. Of the 15,227 patients in the Shinken Database, a singlehospital-based cohort of new patients, 1,214 patients who underwent PCI, was evaluated to determine the differences in clinical outcomes between the elderly $(\geq 75$ years) $(n=$ $260)$ and the non-elderly ( $<75$ years) $(n=954)$ patients. A major adverse cardiac event (MACE) was defined as a composite end point, including all-cause death, myocardial infarction (MI), and target lesion revascularization. Male gender and obesity were less common, and the estimated glomerular filtration rate (eGFR) was significantly lower in the elderly than in the non-elderly. Left ventricular ejection fraction (LVEF) was comparable between these groups. Left main trunk disease and multivessel disease were more common in the elderly than in the non-elderly group. Occurrence of MACE was frequent, and the incidences of all-cause death, cardiac death, and the admission rate for heart failure were significantly higher in the elderly patients. Multivariate analysis showed that prior MI, low eGFR, and poor LVEF were independent predictors for allcause death in the elderly patients. Elderly patients had
\end{abstract}

Electronic supplementary material The online version of this article (doi:10.1007/s00380-013-0339-9) contains supplementary material, which is available to authorized users.

H. Kaneko $(\varangle) \cdot$ J. Yajima $\cdot$ Y. Oikawa $\cdot$ S. Tanaka .

D. Fukamachi - S. Suzuki - K. Sagara - T. Otsuka - S. Matsuno ·

R. Funada - H. Kano - T. Uejima - A. Koike - K. Nagashima ·

H. Kirigaya - H. Sawada - T. Aizawa - T. Yamashita

Department of Cardiovascular Medicine, The Cardiovascular Institute, 3-2-19, Nishiazabu, Minato-ku, Tokyo 106-0031, Japan

e-mail: h-kaneko@cvi.or.jp; kanekohidehiro@gmail.com worse clinical outcomes than the non-elderly patients. Low eGFR and LVEF were independent predictors of all-cause death after PCI, suggesting that left ventricular dysfunction and renal dysfunction might synergistically contribute to the adverse clinical outcomes of the elderly patients undergoing PCI.

Keywords Aging - Japanese - Coronary artery disease . Prognosis

\section{Introduction}

Japan has the highest proportion of elderly citizens in the world. In 1989, only $11.6 \%$ of the population was aged $\geq 65$ years. However, the Ministry of Internal Affairs and Communications recently reported that $23.8 \%$ of the population is aged $\geq 65$ years, and $11.8 \%$ of the population is $\geq 75$ years. In parallel with the aging population in Japan, coronary artery disease (CAD) has become a common degenerative condition. For the management of CAD, elucidating the effect of aging on the clinical characteristics and outcomes of Japanese CAD patients, as well as clarifying the prognostic factors associated with $\mathrm{CAD}$, is important.

The TIME trial showed that patients aged 75 years or older with angina refractory to standard drug therapy benefited more from revascularization than from optimized medical therapy in terms of angina relief and improvement in quality of life; this finding supports the clinical efficacy of revascularization therapy in elderly patients [1]. Because of wide variations in ethnicity, geographic locations, social health care systems, and treatment strategies [2-8], it has been suggested that the clinical outcomes of CAD in Japanese patients are likely to be different from those in the 
Western population. Furthermore, percutaneous coronary intervention (PCI) is preferred and widely performed in CAD patients in Japan.

Clinical studies focusing on elderly Japanese patients undergoing PCI are limited. The prognosis of elderly Japanese CAD patients treated using PCI remains to be determined. We conducted a hospital-based cohort study using the Shinken Database 2004-2010 to investigate the prevalence and prognosis of patients with cardiovascular diseases in Japan [9]. The present study, which included patients who underwent PCI $(n=1,214)$, aimed to identify the clinical characteristics and outcomes in elderly CAD patients after PCI in a Japanese urban city.

\section{Patients and methods}

Study patients and protocols

The Shinken Database included all new patients visiting the Cardiovascular Institute in Tokyo, Japan ("Shinken" is an abbreviated name for the hospital in Japanese), and excluded cancer patients and any foreign travelers. This hospital-based database was established for the surveillance of the prevalence and prognosis of cardiovascular diseases in urban areas in Japan [10]. The registry was started in June 2004, and thereafter patients have been continually registered to the database annually. Data entered into the database between June 2004 and March 2011 (Shinken Database 2004-2010), which included 15,227 new patients, were used in the present study. Of these patients, only those who underwent PCI $(n=1214)$ were enrolled in the study. We obtained the following data: age; gender; height; body weight; history of prior myocardial infarction (MI), PCI, and coronary artery bypass graft (CABG); coronary risk factors; laboratory data; and medications at primary PCI. Ultrasound cardiography was routinely performed before PCI.

\section{Patient follow-up}

The health status details of patients and the incidence of cardiovascular events and mortality were maintained in the database, and could be accessed through a link to the medical records of the hospital and through survey documents sent once a year to those who stopped hospital visits or were referred to other hospitals.

In the present analysis, the follow-up data recorded after April 1, 2011, were excluded. Therefore, the end of the follow-up period was defined by one of the following three criteria: (1) death before March 31, 2011; (2) the date of final hospital visit or response to our survey documents on prognosis, with a confirmation of the patient being alive on
March 31, 2011; and (3) March 31, 2011, if the dates of death, final hospital visit, or final response to survey documents on prognosis were later than April 1, 2011.

\section{Ethics}

The ethical committee at the Cardiovascular Institute authorized this study, and all patients gave written informed consent.

\section{Definitions}

We defined elderly patients ( $\geq 75$ years), whereas nonelderly patients ( $\leq 75$ years). The death of patients was confirmed using the medical records of our hospital or via the information obtained from follow-up visits. Body mass index (BMI) was calculated at initial PCI by dividing the patient's measured weight $(\mathrm{kg})$ by the square of the height $(\mathrm{m})$, and obesity was defined as a BMI of $\geq 25 \mathrm{~kg} / \mathrm{m}^{2}$. The estimated glomerular filtration rate (eGFR) was calculated using the following GFR equation: GFR $=194 \times($ serum creatinine $)-1.094 \times($ age $)-$ $0.287 \times(0.739$, if female $)$ [11]. Target lesion revascularization (TLR) was defined as any repeat revascularization procedure (percutaneous or surgical) at the original target lesion site, which included the stented area plus a margin (typically $5 \mathrm{~mm}$ proximal and distal to the stent). A major adverse cardiac event (MACE) was defined as a composite end point of all-cause death, MI, and TLR. Cardiovascular death included death resulting from acute myocardial infarction, sudden cardiac death, death due to heart failure, death due to stroke, and death due to other cardiovascular causes.

\section{Statistical analysis}

The categorical and continuous data of patients are presented as number $(\%)$ and mean \pm standard deviation, respectively. The unpaired $t$ test was used for comparisons of continuous variables between the two groups. Chisquare analysis was used to compare categorical variables. Long-term event-free survival was estimated using the Kaplan-Meier curves, and the log-rank test was used to assess the significance of differences between elderly and non-elderly patients. Univariate Cox regression analysis was used to identify the cofactors with significant effects on all-cause death and cardiovascular death. Multivariate Cox regression analysis was performed to determine the independent prognostic factors for all-cause death and cardiovascular death. $P<0.05$ was considered to indicate statistical significance. These analyses were performed using SPSS version 19.0 software (SPSS, Chicago, IL, USA). 


\section{Results}

\section{Patients' characteristics}

Of the 1214 patients, $260(21 \%)$ were elderly ( $\geq 75$ years) and $954(79 \%)$ were non-elderly. The median follow-up period was $1032 \pm 704$ days. Mean ages were $80.0 \pm 4.3$ years in the elderly patients and $61.4 \pm 8.4$ years in the non-elderly patients. Prevalence of stable angina pectoris and acute coronary syndrome (ACS) (non-ST elevation ACS and ST-elevation myocardial infarction) were comparable between the elderly and the non-elderly patients. Male gender (64.6 vs $87.3 \%, P<0.001$ ), dyslipidemia (51.2 vs $61.8 \%, P=0.002)$, obesity (22.2 vs $43.8 \%, P<$ 0.001 ), cigarette smoking (16.2 vs $42.5 \%, P<0.001)$, and family history of CAD (11.9 vs $17.0 \%, P=0.048)$ were less common in the elderly patients than in the non-elderly patients. Levels of total cholesterol (184.8 \pm 35.3 vs 194.4 $\pm 39.6 \mathrm{mg} / \mathrm{dl}, P=0.001)$, low-density lipoprotein (LDL) cholesterol $(108.7 \pm 30.5$ vs $114.4 \pm 33.9 \mathrm{mg} / \mathrm{dl}, P=$ $0.010)$, triglycerides (TG) (111.4 \pm 53.2 vs $162.0 \pm 118.8$ $\mathrm{mg} / \mathrm{dl}, P<0.001)$, and hemoglobin A1c (HbA1c) $(6.0 \pm$ $1.1 \%$ vs $6.2 \pm 1.3 \%, P=0.034$ ) were significantly lower in the elderly than in the non-elderly patients. The highdensity lipoprotein (HDL) cholesterol level (54.2 \pm 14.4 vs $50.0 \pm 14.8 \mathrm{mg} / \mathrm{dl}, P<0.001)$ was significantly higher in the elderly than in the non-elderly patients.

The use of dual antiplatelet therapy (93.1 vs $96.0 \%, P=$ $0.045)$ and statins (50.4 vs $63.4 \%, P<0.001)$ was less common in the elderly than in the non-elderly patients. The use of vasodilators (46.2 vs $32.9 \%, P<0.001$ ), diuretics (21.2 vs $10.3 \%, P<0.001$ ), and aldosterone antagonists (9.2 vs $4.7 \%, P=0.005$ ) was more common in the elderly than in the non-elderly patients. The prevalence of baremetal stents and drug-eluting stents was comparable between the elderly and the non-elderly patients (Table 1).

\section{Echocardiography findings}

Ultrasound cardiography showed that the left ventricular ejection fraction (LVEF) $(62 \pm 14$ vs $62 \pm 13 \%, P=$ 0.985) was comparable between the elderly and nonelderly patients (Table 1).

\section{Angiographic findings}

Coronary angiography showed that the number of patients with left main trunk (LMT) disease (10.4 vs $4.7 \%, P=$ $0.001)$ and multivessel disease (MVD) (65.8 vs $58.5 \%, P=$ $0.034)$ was higher in the elderly than in the non-elderly group (Table 1).
Table 1 Patients' background characteristics

\begin{tabular}{|c|c|c|c|}
\hline & Non-elderly $(n=954)$ & Elderly $(n=260)$ & $P$ value \\
\hline Age (years) & $61.4 \pm 8.4$ & $80.0 \pm 4.3$ & $<0.001$ \\
\hline Male sex & $833 / 954(87.3)$ & $168 / 260(64.6)$ & $<0.001$ \\
\hline SAP & $595 / 954(62.4)$ & $152 / 260(58.5)$ & 0.251 \\
\hline ACS & $359 / 954$ (37.6) & $108 / 260(41.5)$ & 0.251 \\
\hline Non-STE ACS & 186/954 (19.5) & $52 / 260(20.0)$ & \\
\hline STEMI & 173/954 (18.1) & $56 / 260(21.5)$ & \\
\hline Prior MI & 107/954 (11.2) & $28 / 260(10.8)$ & 0.839 \\
\hline Prior PCI & $100 / 954(10.5)$ & $29 / 260(11.2)$ & 0.755 \\
\hline Prior CABG & $34 / 954(3.6)$ & $13 / 260(5.0)$ & 0.287 \\
\hline Hypertension & $615 / 954(64.5)$ & $164 / 260(63.1)$ & 0.679 \\
\hline Diabetes mellitus & $332 / 954(34.8)$ & $79 / 260(30.4)$ & 0.182 \\
\hline Dyslipidemia & $590 / 954(61.8)$ & $133 / 260(51.2)$ & 0.002 \\
\hline Hyperuricemia & 237/954 (24.8) & $67 / 260(25.8)$ & 0.760 \\
\hline Obesity & $417 / 953(43.8)$ & $56 / 252(22.2)$ & $<0.001$ \\
\hline Cigarette smoking & $405 / 954(42.5)$ & $42 / 260(16.2)$ & $<0.001$ \\
\hline Family history & $162 / 954(17.0)$ & $31 / 260(11.9)$ & 0.048 \\
\hline eGFR $\left(\mathrm{ml} / \mathrm{min} / 1.73 \mathrm{~m}^{2}\right)$ & $70.1 \pm 21.4$ & $57.3 \pm 18.8$ & $<0.001$ \\
\hline $\begin{array}{l}\text { Total cholesterol } \\
\qquad(\mathrm{mg} / \mathrm{dl})\end{array}$ & $194.4 \pm 39.6$ & $184.8 \pm 35.3$ & 0.001 \\
\hline $\begin{array}{l}\text { LDL cholesterol } \\
\qquad(\mathrm{mg} / \mathrm{dl})\end{array}$ & $114.4 \pm 33.9$ & $108.7 \pm 30.4$ & 0.010 \\
\hline $\begin{array}{l}\text { HDL cholesterol } \\
\qquad(\mathrm{mg} / \mathrm{dl})\end{array}$ & $50.0 \pm 14.8$ & $54.2 \pm 14.4$ & $<0.001$ \\
\hline TG (mg/dl) & $162.0 \pm 118.9$ & $111.4 \pm 53.2$ & $<0.001$ \\
\hline Glucose (mg/dl) & $134.0 \pm 55.8$ & $135.5 \pm 53.3$ & 0.709 \\
\hline HbAlc (\%) & $6.2 \pm 1.3$ & $6.0 \pm 1.1$ & 0.034 \\
\hline LVEF (\%) & $61.6 \pm 12.6$ & $61.6 \pm 14.3$ & 0.985 \\
\hline DAPT & 916/954 (96.0) & $242 / 260(93.1)$ & 0.045 \\
\hline Anticoagulant therapy & $67 / 954(7.0)$ & $26 / 260(10.0)$ & 0.110 \\
\hline Statins & $605 / 954(63.4)$ & $131 / 260(50.4)$ & $<0.001$ \\
\hline$\beta$-Blockers & $354 / 954(37.1)$ & $94 / 260(36.2)$ & 0.778 \\
\hline ACE-Is & $155 / 954(16.2)$ & $41 / 260(15.8)$ & 0.853 \\
\hline ARBs & $363 / 954(38.1)$ & $107 / 260(41.2)$ & 0.362 \\
\hline RAS-Is & $506 / 954(53.0)$ & $145 / 260(55.8)$ & 0.434 \\
\hline CCBs & $426 / 954(44.7)$ & $113 / 260(43.5)$ & 0.732 \\
\hline Vasodilators & $314 / 954$ (32.9) & $120 / 260(46.2)$ & $<0.001$ \\
\hline Diuretics & 98/954 (10.3) & $55 / 260(21.2)$ & $<0.001$ \\
\hline Aldosterone antagonists & 45/954 (4.7) & $24 / 260(9.2)$ & 0.005 \\
\hline Antidiabetic drugs & 189/954 (19.8) & 49/260 (18.8) & 0.728 \\
\hline Thiazolidinediones & $33 / 954(3.5)$ & $7 / 260(2.7)$ & 0.539 \\
\hline Insulin & $33 / 954(3.5)$ & $5 / 260(1.9)$ & 0.207 \\
\hline LMT & $45 / 954(4.7)$ & $27 / 260(10.4)$ & 0.001 \\
\hline MVD & $558 / 954(58.5)$ & $171 / 260(65.8)$ & 0.034 \\
\hline BMS & 303/954 (31.8) & $90 / 260(34.6)$ & 0.383 \\
\hline DES & 635/954 (66.6) & $161 / 260(61.9)$ & 0.163 \\
\hline
\end{tabular}

Data are expressed as mean \pm standard deviation, or counts (percentage)

$S A P$ stable angina pectoris, ACS acute coronary syndrome, Non-STE ACS nonST-elevation ACS, STEMI ST-elevation myocardial infarction, Prior MI prior history of myocardial infarction, Prior PCI prior history of percutaneous coronary intervention, Prior $C A B G$ prior history of coronary artery bypass graft, $e G F R$ estimated glomerular filtration rate, $L D L$ low-density lipoprotein, $H D L$ high-density lipoprotein, $T G$ triglyceride, $L V E F$ left ventricular ejection fraction, $D A P T$ dual antiplatelet therapy, Statin 3-hydroxy-3-methylglutaryl coenzyme A (HMG-CoA) inhibitor, $A C E-I$ angiotensin-converting enzyme inhibitor, $A R B$ angiotensin II receptor blocker, $R A S-I$ renin-angiotensin system inhibitor, $C C B$ calcium-channel blocker, $L M T$ left main trunk disease, $M V D$ multivessel disease, $B M S$ bare-metal stent, $D E S$ drug-eluting stent 


\section{Clinical outcomes}

Overall, all-cause death occurred in 28 elderly patients and 32 non-elderly patients. There were 60 and 194 composite end points, 7 and 10 cardiac deaths, 5 and 16 MI occurrences, 22 and 27 readmissions for heart failure, and 35 and 163 TLR occurrences in the elderly and non-elderly patients, respectively (Table 2). Kaplan-Meier curves and the log-rank test revealed that the frequency of MACE tended to be higher in the elderly than in the non-elderly patients $(P=0.149)$, and that the frequency of all-cause death $(P<0.001)$, cardiac death $(P=0.025)$, and readmission for heart failure $(P<0.001)$ were significantly higher in the elderly than in the non-elderly patients. Frequency of $\mathrm{MI}(P=0.594)$ and $\operatorname{TLR}(P=0.433)$ were comparable between the two groups (Fig. 1).

Predictors of all-cause death and cardiovascular death

Univariate Cox regression analysis showed that factors associated with all-cause death after PCI in the elderly patients included ACS, prior history of MI, eGFR, levels of total cholesterol and glucose, LVEF, and the use of statins, calcium-channel blockers, diuretics, and aldosterone antagonists (Table 3), whereas those in non-elderly patients included age, prior history of CABG surgery, dyslipidemia, cigarette smoking, eGFR, glucose level, LVEF, multivessel coronary disease, and the use of statins, $\beta$-blockers, and insulin (Table 5). Multivariate Cox regression analysis of the significant and marginally significant predictors $(P<$ $0.10)$ in the univariate model revealed that the independent predictors of death in the elderly patients were prior history of MI, low eGFR, and poor LVEF in the elderly patients undergoing PCI (Table 4), whereas those in the non-elderly patients were prior history of PCI, higher glucose level,

Table 2 Clinical outcomes

\begin{tabular}{lllr}
\hline & $\begin{array}{l}\text { Non-elderly } \\
(n=954)\end{array}$ & $\begin{array}{l}\text { Elderly } \\
(n=260)\end{array}$ & $P$ value \\
\hline MACE & $194 / 954(20.3)$ & $60 / 260(23.1)$ & 0.335 \\
All-cause death & $32 / 954(3.4)$ & $28 / 260(10.8)$ & $<0.001$ \\
Cardiac death & $10 / 954(1.0)$ & $7 / 260(2.7)$ & 0.046 \\
Cardiovascular death & $12 / 954(1.3)$ & $7 / 260(2.7)$ & 0.099 \\
$\begin{array}{l}\text { MI } \\
\text { Readmission for heart } \\
\text { failure }\end{array}$ & $16 / 954(1.7)$ & $5 / 260(1.9)$ & 0.787 \\
TLR & $163 / 954(2.8)$ & $22 / 260(8.5)$ & $<0.001$ \\
\hline
\end{tabular}

Data are expressed as counts (percentage)

MACE major adverse cardiac event, $M I$ myocardial infarction, TLR target lesion revascularization
Fig. 1 Kaplan-Meier curves for survival rates without major adverse cardiac events $(M A C E)$ (a), all-cause death (b), cardiac death (c), myocardial infarction $(M I)(\mathbf{d})$, admission for heart failure (e), and target lesion revascularization (TLR) (f). Solid line elderly patients, dotted line non-elderly patients

poor LVEF, and absence of statin treatment (Table 6). Cox regression analysis showed that independent predictors of cardiovascular death after PCI included poor LVEF in the elderly patients, and female gender, low eGFR, and poor LVEF in the non-elderly patients (see Supplementary table, Table S1-4).

\section{Discussion}

The present study showed that elderly Japanese CAD patients who underwent PCI had higher incidences of allcause death and cardiac death and higher rates of admission for heart failure than non-elderly patients. Multivariate Cox regression analysis showed that prior history of $\mathrm{MI}$, low eGFR, and poor LVEF were independent predictors of allcause death in elderly patients undergoing PCI.

Because the prevalence of CAD and other comorbidities is high among the elderly population, conservative pharmacologic treatment tends to be selected as the therapy of choice to reduce the risk of complications. However, because of advances in technical skills and better medical management, PCI has been associated with improved clinical outcomes in elderly patients [12, 13]. Moreover, elderly patients paradoxically had greater absolute risk reductions associated with surgical or percutaneous revascularization than younger patients in the setting of acute MI, owing to the higher baseline risk for significant morbidity and mortality $[14,15]$. Because Japan has become an aging society with a consequent increase in the prevalence of CAD, the clinical significance of improved outcomes in elderly Japanese patients after PCI is very important.

In the present study, $21 \%$ of the patients were older than 75 years, and elderly patients had higher incidences of allcause death and cardiac death as well as higher rates of admission for heart failure than non-elderly patients. Although the incidences of all-cause death and cardiac death were higher in the elderly patients than in the nonelderly patients after PCI, the clinical outcomes were comparable with those of other clinical studies conducted in Western countries [14, 16]. Furthermore, considering that $41.5 \%$ of elderly patients underwent PCI for ACS, this study suggests that the clinical outcomes of elderly Japanese patients after PCI were acceptable in clinical practice. Thus, revascularization therapy should be indicated in elderly patients when appropriate, and should not be avoided owing to higher age or greater morbidity. 
A

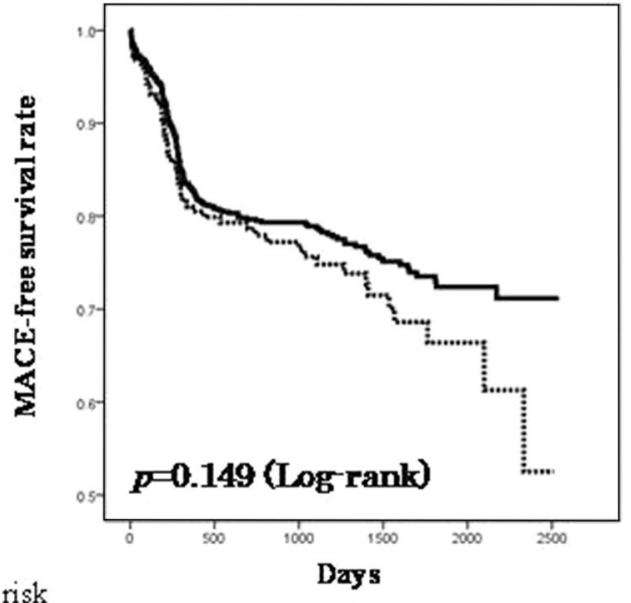

Patients at risk Nom Elderly

C

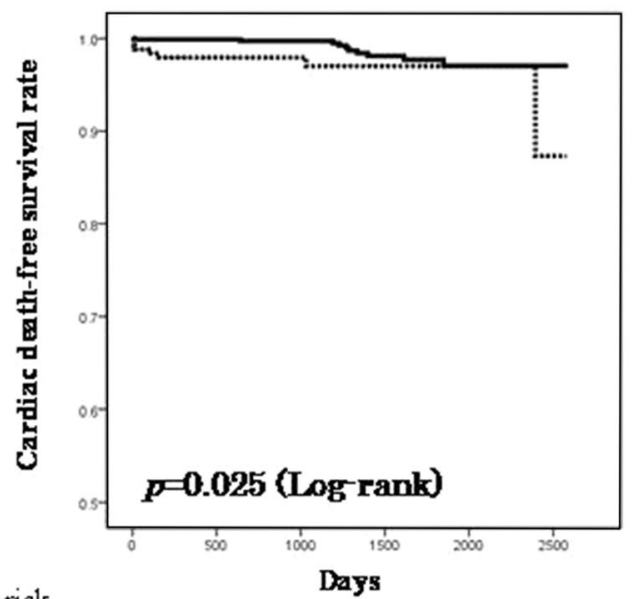

Patients at risk Nownerly $\begin{array}{llllll}954 & 682 & 493 & 274 & 108 & 6 \\ 260 & 153 & 107 & 62 & 23 & 2\end{array}$

E

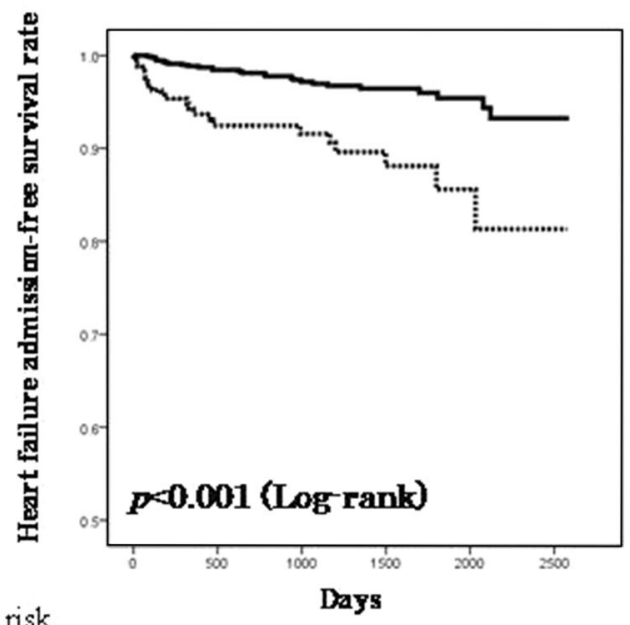

Patients at risk Non. Eldery
Enderly $\begin{array}{llllll}954 & 545 & 391 & 219 & 79 & 3 \\ 260 & 133 & 97 & 54 & 18 & 1\end{array}$
Pati ents at risk Non-Eldery Enderly

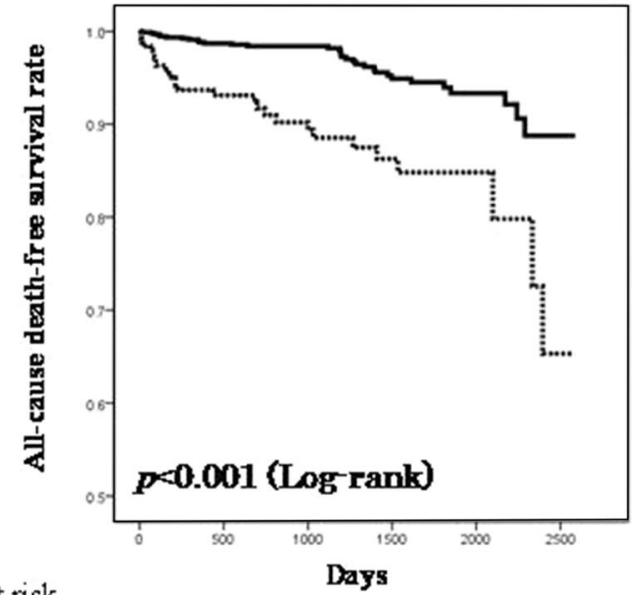

D

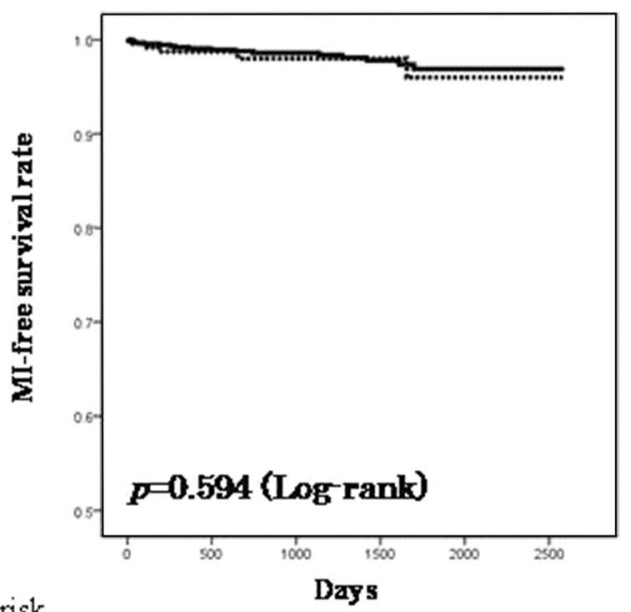

Pati ents at risk

Non-Elderly $\begin{array}{llllll}954 & 674 & 485 & 269 & 103 & 5 \\ 260 & 152 & 107 & 62 & 23 & 2\end{array}$

F

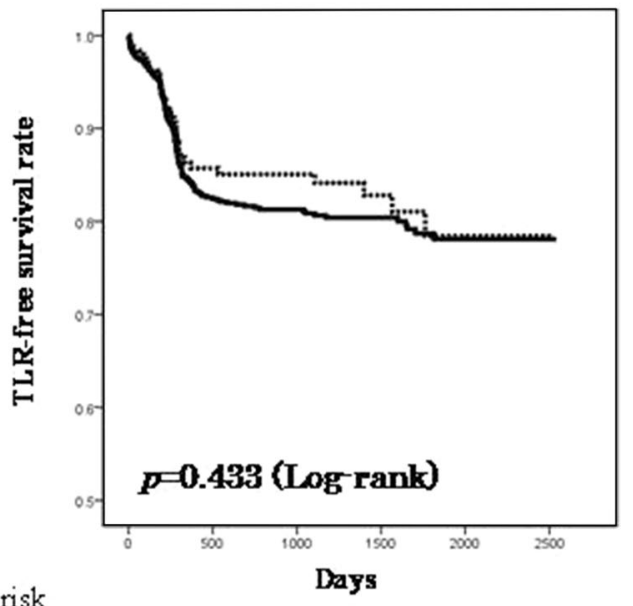

Patients at risk Eon-Elderly $\begin{array}{llllll}954 & 550 & 395 & 222 & 80 & 3 \\ 260 & 133 & 97 & 54 & 18 & 1\end{array}$ 
Multivariate Cox regression analysis showed that independent predictors of death included prior history of MI, low eGFR, and poor LVEF in elderly patients, and prior history of PCI, higher glucose level, poor LVEF, and absence of statin treatment in non-elderly patients. Left ventricular function and renal function might have stronger predictive value in the elderly patients after PCI. Cardiac failure and renal dysfunction synergistically magnify the poor clinical outcomes associated with either disease alone [17].

Optimized medical therapy that includes the use of $\beta$-blockers, renin-angiotensin system inhibitor (RAS-I)s, and statins is crucial in elderly patients. The TIME trial strongly encouraged optimized medical therapy in elderly patients undergoing PCI [18]. As vasospastic angina is common in Japanese patients, administration of $\beta$-blockers tends to be avoided in clinical practice [19]. In fact, only $36.2 \%$ of elderly patients used $\beta$-blockers, whereas $46.2 \%$ of elderly patients used vasodilators. In addition, RAS-Is were administered to only $55.8 \%$ of elderly CAD patients after PCI. Unfortunately, an increase in creatinine levels is sometimes associated with the administration of RAS-Is in the presence of underlying renal disease, thereby creating a therapeutic dilemma [20]. Because clinical studies support the benefits of $\beta$-blockers [21-23] and RAS-Is [24, 25] for $\mathrm{CAD}$, the use of these agents is recommended in CAD patients when the side effects are acceptable, even in elderly patients and in those with chronic kidney disease (CKD). Statins are also promising agents for the treatment of CAD, and their effects have been studied extensively [26-28]. In Western countries, statins are administered to $80-90 \%$ of CAD patients [29]. By contrast, only $50.4 \%$ of the patients included in the present study received statins after PCI. Although statins were prescribed to patients, they were often not consumed or discontinued by the patients for various reasons. Caution should be exercised when prescribing statins to elderly patients with CKD because of the increased risk of toxicity, particularly the risk of myopathy. Optimized medical treatment is believed to reduce the morbidity and mortality of CAD patients, although only a limited number of patients included in the present study received the medications listed above. Thus there may be room for further improvement in drug therapy. Moreover, we do not have the data regarding the continued use of medications in this study. Further studies will be needed to clarify the impact of the optimal medical treatment on long-term clinical outcomes of Japanese elderly CAD patients after PCI.

In this study, we evaluated the clinical outcomes of elderly CAD patients undergoing PCI. However, Kimura et al. [30] reported better survival rates in patients older than 75 years undergoing CABG surgery, especially in high-risk patients, including those with triple-vessel
Table 3 Unadjusted predictors for all-cause death of elderly patients

\begin{tabular}{|c|c|c|c|}
\hline & $P$ value & Hazard ratio & $95 \% \mathrm{CI}$ \\
\hline Age (years) & 0.068 & 1.073 & $0.995-1.158$ \\
\hline Male sex & 0.505 & 0.772 & $0.360-1.654$ \\
\hline Obesity & 0.107 & 0.367 & $0.109-1.242$ \\
\hline ACS & 0.002 & 3.661 & $1.612-8.316$ \\
\hline Prior MI & 0.031 & 2.742 & $1.100-6.836$ \\
\hline Prior PCI & 0.882 & 0.896 & $0.211-3.806$ \\
\hline Prior $\mathrm{CABG}$ & 0.399 & 0.045 & $0.000-61.236$ \\
\hline Hypertension & 0.138 & 0.570 & $0.272-1.198$ \\
\hline Diabetes mellitus & 0.583 & 1.242 & $0.573-2.692$ \\
\hline Dyslipidemia & 0.066 & 0.484 & $0.223-1.050$ \\
\hline Hyperuricemia & 0.107 & 1.870 & $0.873-4.004$ \\
\hline Cigarette smoking & 0.661 & 0.789 & $0.274-2.275$ \\
\hline Family history & 0.768 & 0.835 & $0.252-2.769$ \\
\hline eGFR $\left(\mathrm{ml} / \mathrm{min} / 1.73 \mathrm{~m}^{2}\right)$ & 0.005 & 0.972 & $0.953-0.991$ \\
\hline Total cholesterol (mg/dl) & 0.035 & 0.986 & $0.973-0.999$ \\
\hline LDL cholesterol (mg/dl) & 0.127 & 0.989 & $0.975-1.003$ \\
\hline HDL cholesterol (mg/dl) & 0.469 & 0.989 & $0.961-1.018$ \\
\hline TG (mg/dl) & 0.053 & 0.990 & $0.980-1.000$ \\
\hline Glucose (mg/dl) & 0.024 & 1.006 & $1.001-1.012$ \\
\hline HbA1c $(\%)$ & 0.742 & 0.936 & $0.634-1.384$ \\
\hline LVEF $(\%)$ & $<0.001$ & 0.938 & $0.916-0.961$ \\
\hline DAPT & 0.370 & 0.613 & $0.211-1.787$ \\
\hline Anticoagulant therapy & 0.087 & 1.199 & $0.359-4.001$ \\
\hline Statins & 0.007 & 0.290 & $0.117-0.717$ \\
\hline$\beta$-Blockers & 0.177 & 0.554 & $0.235-1.307$ \\
\hline ACE-Is & 0.663 & 1.243 & $0.466-3.315$ \\
\hline ARBs & 0.514 & 0.767 & $0.346-1.700$ \\
\hline RAS-Is & 0.837 & 0.925 & $0.440-1.945$ \\
\hline $\mathrm{CCBs}$ & 0.013 & 0.315 & $0.127-0.781$ \\
\hline Vasodilators & 0.719 & 0.871 & $0.412-1.843$ \\
\hline Diuretics & 0.043 & 2.321 & $1.026-5.248$ \\
\hline Aldosterone antagonist & 0.001 & 4.267 & $1.778-10.238$ \\
\hline Antidiabetic drugs & 0.151 & 0.348 & $0.082-1.468$ \\
\hline Thiazolidinediones & 0.517 & 0.047 & $0.000-484.579$ \\
\hline Insulin & 0.899 & 0.875 & $0.113-6.783$ \\
\hline LMT & 0.057 & 2.434 & $0.975-6.075$ \\
\hline MVD & 0.728 & 1.157 & $0.508-2.635$ \\
\hline
\end{tabular}

$\overline{A C S}$ acute coronary syndrome, Prior $M I$ prior history of myocardial infarction, Prior PCI prior history of percutaneous coronary intervention, Prior $C A B G$ prior history of coronary artery bypass graft, $e G F R$ estimated glomerular filtration rate, $L D L$ low-density lipoprotein, $H D L$ high-density lipoprotein, $T G$ triglyceride, $L V E F$ left ventricular ejection fraction, DAPT dual antiplatelet therapy, Statin HMG-CoA inhibitor, $A C E-I$ angiotensin-converting enzyme inhibitor, $A R B$ angiotensin II receptor blocker, $R A S-I$ renin-angiotensin system inhibitor, $C C B$ calcium-channel blocker, $L M T$ left main trunk disease, $M V D$ multivessel disease, $C I$ confidence interval

disease and diabetes. Similarly, better survival after CABG in elderly individuals was also reported in the APPROACH registry [14] and the AWESOME trial [31]. Under clinical 
Table 4 Adjusted determinants of all-cause death of elderly patients

\begin{tabular}{lcrll}
\hline & $\begin{array}{l}\text { Univariate } \\
P \text { value }\end{array}$ & $P$ value & $\begin{array}{l}\text { Hazard } \\
\text { ratio }\end{array}$ & $95 \%$ CI \\
\hline Age & 0.068 & 0.656 & 0.979 & $0.891-1.076$ \\
ACS & 0.002 & 0.681 & 1.237 & $0.448-3.419$ \\
Prior MI & 0.031 & 0.012 & 3.894 & $1.351-11.225$ \\
eGFR & 0.005 & 0.010 & 0.967 & $0.944-0.993$ \\
Total & 0.035 & 0.955 & 1.000 & $0.984-1.017$ \\
$\quad$ cholesterol & & & & \\
TG & 0.053 & 0.555 & 0.997 & $0.985-1.008$ \\
Glucose & 0.024 & 0.759 & 1.001 & $0.994-1.008$ \\
LVEF & $<0.001$ & $<0.001$ & 0.934 & $0.904-0.966$ \\
Anticoagulant & 0.087 & 0.970 & 0.970 & $0.202-4.6635$ \\
$\quad$ therapy & & & & \\
Statin & 0.007 & 0.152 & 0.477 & $0.173-1.314$ \\
CCB & 0.013 & 0.163 & 0.470 & $0.163-1.359$ \\
Diuretics & 0.043 & 0.360 & 0.531 & $0.161-1.757$ \\
Aldosterone & 0.001 & 0.576 & 1.430 & $0.408-5.017$ \\
$\quad$ antagonist & & & & \\
LMT & 0.057 & 0.338 & 0.418 & $0.109-1.598$ \\
\hline ACS & & &
\end{tabular}

ACS acute coronary syndrome, Prior MI history of myocardial infarction, $e G F R$ estimated glomerular filtration rate, $T G$ triglyceride, $L V E F$ left ventricular ejection fraction, $D A P T$ dual antiplatelet therapy, Statin HMG-CoA inhibitor, $C C B$ calcium-channel blocker, $L M T$ left main trunk disease, $C I$ confidence interval

settings, elderly patients with significant comorbidities tend to be referred for PCI because of its less invasive nature. Such a selection bias may be responsible for the discrepancies between these studies. To justify the use of PCI as a treatment strategy, the clinical outcomes of elderly CAD patients treated using PCI and CABG should be compared.

Study limitations

The present study has several limitations. The number of patients was small, so the statistical power may not be strong enough for any negative data to be conclusive. Further investigation of a large study population is necessary. In addition, our hospital is a single-department cardiovascular teaching facility, and the results of this study cannot be generalized to all medical centers.

\section{Conclusion}

Elderly Japanese patients who underwent PCI had higher incidences of all-cause death and cardiac death in comparison with non-elderly patients. Poor left ventricular function and renal dysfunction were independent predictors
Table 5 Unadjusted predictors for all-cause death of non-elderly patients

\begin{tabular}{|c|c|c|c|}
\hline & $P$ value & Hazard ratio & $95 \% \mathrm{CI}$ \\
\hline Age & 0.006 & 1.079 & $1.022-1.138$ \\
\hline Male sex & 0.878 & 0.928 & $0.357-2.413$ \\
\hline Obesity & 0.051 & 0.450 & $0.202-1.003$ \\
\hline ACS & 0.981 & 1.009 & $0.498-2.043$ \\
\hline Prior MI & 0.184 & 1.827 & $0.751-4.442$ \\
\hline Prior PCI & 0.098 & 2.115 & $0.870-5.139$ \\
\hline Prior CABG & 0.032 & 3.694 & $1.121-12.173$ \\
\hline Hypertension & 0.810 & 0.917 & $0.452-1.860$ \\
\hline Diabetes mellitus & 0.107 & 1.770 & $0.884-3.546$ \\
\hline Dyslipidemia & 0.037 & 0.472 & $0.233-0.956$ \\
\hline Hyperuricemia & 0.895 & 0.947 & $0.425-2.111$ \\
\hline Cigarette smoking & 0.010 & 0.333 & $0.144-0.771$ \\
\hline Family history & 0.053 & 0.140 & $0.019-1.025$ \\
\hline eGFR & $<0.001$ & 0.967 & $0.955-0.980$ \\
\hline Total cholesterol & 0.281 & 0.995 & $0.985-1.004$ \\
\hline LDL cholesterol & 0.086 & 0.990 & $0.978-1.001$ \\
\hline HDL cholesterol & 0.237 & 1.012 & $0.992-1.031$ \\
\hline TG & 0.136 & 0.996 & $0.991-1.001$ \\
\hline Glucose & $<0.001$ & 1.008 & $1.004-1.012$ \\
\hline $\mathrm{HbA1c}$ & 0.173 & 1.171 & $0.933-1.470$ \\
\hline LVEF & $<0.001$ & 0.948 & $0.929-0.967$ \\
\hline DAPT & 0.828 & 0.853 & $0.203-3.579$ \\
\hline Anticoagulant therapy & 0.365 & 0.398 & $0.054-2.918$ \\
\hline Statins & 0.004 & 0.329 & $0.155-0.696$ \\
\hline$\beta$-Blockers & 0.009 & 2.611 & $1.275-5.345$ \\
\hline ACE-Is & 0.717 & 0.837 & $0.321-2.185$ \\
\hline ARBs & 0.529 & 0.780 & $0.360-1.689$ \\
\hline RAS-Is & 0.441 & 0.759 & $0.376-1.531$ \\
\hline CCBs & 0.856 & 0.937 & $0.462-1.898$ \\
\hline Vasodilators & 0.280 & 1.469 & $0.731-2.955$ \\
\hline Diuretics & $<0.001$ & 5.318 & $2.563-11.038$ \\
\hline Aldosterone antagonist & 0.062 & 2.726 & $0.953-7.801$ \\
\hline Antidiabetic drugs & 0.374 & 1.438 & $0.646-3.202$ \\
\hline Thiazolidinediones & 0.174 & 2.286 & $0.694-7.534$ \\
\hline Insulin & 0.043 & 3.426 & $1.041-11.273$ \\
\hline LMT & 0.427 & 1.788 & $0.426-7.505$ \\
\hline MVD & 0.008 & 3.648 & $1.405-9.475$ \\
\hline
\end{tabular}

$A C S$ acute coronary syndrome, Prior $M I$ prior history of myocardial infarction, Prior PCI prior history of percutaneous coronary intervention, Prior $C A B G$ prior history of coronary artery bypass graft, $e G F R$ estimated glomerular filtration rate, $L D L$ low-density lipoprotein, $H D L$ high-density lipoprotein, $T G$ triglyceride, $L V E F$ left ventricular ejection fraction, DAPT dual antiplatelet therapy, Statin HMG-CoA inhibitor, $A C E-I$ angiotensin-converting enzyme inhibitor, $A R B$ angiotensin II receptor blocker, RAS-Is renin-angiotensin system inhibitors, $C C B$ calcium-channel blocker, $L M T$ left main trunk disease, $M V D$ multivessel disease, $C I$ confidence interval 
Table 6 Adjusted determinants of all-cause death of non-elderly patients

\begin{tabular}{|c|c|c|c|c|}
\hline & $\begin{array}{l}\text { Univariate } \\
P \text { value }\end{array}$ & $P$ value & $\begin{array}{l}\text { Hazard } \\
\text { ratio }\end{array}$ & $95 \% \mathrm{CI}$ \\
\hline Age & 0.006 & 0.090 & 1.062 & $0.991-1.139$ \\
\hline Obesity & 0.051 & 0.144 & 0.485 & $0.183-1.281$ \\
\hline Prior PCI & 0.098 & 0.025 & 3.351 & $1.167-9.618$ \\
\hline Prior CABG & 0.032 & 0.195 & 0.296 & $0.047-1.868$ \\
\hline Dyslipidemia & 0.037 & 0.386 & 1.522 & $0.589-3.931$ \\
\hline $\begin{array}{l}\text { Cigarette } \\
\text { smoking }\end{array}$ & 0.010 & 0.379 & 0.649 & $0.248-1.700$ \\
\hline Family history & 0.053 & 0.955 & 0.000 & \\
\hline eGFR & $<0.001$ & 0.146 & 0.989 & $0.974-1.004$ \\
\hline LDL & 0.086 & 0.462 & 1.005 & $0.992-1.018$ \\
\hline Glucose & $<0.001$ & 0.014 & 1.007 & $1.001-1.012$ \\
\hline LVEF & $<0.001$ & 0.008 & 0.962 & $0.934-0.990$ \\
\hline Statins & 0.004 & 0.012 & 0.286 & $0.108-0.759$ \\
\hline$\beta$-Blockers & 0.009 & 0.080 & 2.114 & $0.915-4.882$ \\
\hline Diuretics & $<0.001$ & 0.620 & 1.286 & $0.475-3.483$ \\
\hline $\begin{array}{r}\text { Aldosterone } \\
\text { antagonist }\end{array}$ & 0.062 & 0.146 & 0.285 & $0.052-1.550$ \\
\hline Insulin & 0.043 & 0.106 & 3.480 & $0.768-15.761$ \\
\hline MVD & 0.008 & 0.086 & 2.512 & $0.877-7.195$ \\
\hline
\end{tabular}

Prior PCI prior history of percutaneous coronary intervention, Prior $C A B G$ prior history of coronary artery bypass graft, $e G F R$ estimated glomerular filtration rate, $L D L$ low-density lipoprotein, $L V E F$ left ventricular ejection fraction, $M V D$ multivessel disease, $C I$ confidence interval

of all-cause death in elderly patients, suggesting that left ventricular dysfunction and renal dysfunction may synergistically contribute to the adverse clinical outcomes in elderly patients undergoing PCI.

Acknowledgments We thank Shiro Ueda and Nobuko Ueda from Medical Edge Co. Ltd. for assembling the database by using the Clinical Study Supporting System (CliSSS); Ineko Hayakawa, Hiroaki Arai, and Hiroshi Aoki for data management and system administration; and the entire staff of the intervention laboratory in our institute.

Conflict of interest None of the authors has any conflict of interest pertaining to this article.

Open Access This article is distributed under the terms of the Creative Commons Attribution License which permits any use, distribution, and reproduction in any medium, provided the original author(s) and the source are credited.

\section{References}

1. TIME Investigators (2001) Trial of invasive versus medical therapy in elderly patients with chronic symptomatic coronaryartery disease (TIME): a randomised trial. Lancet 358:951-7
2. Yusuf S, Flather M, Pogue J, Hunt D, Varigos J, Piegas L, Avezum A, Anderson J, Keltai M, Budaj A, Fox K, Ceremuzynski L (1998) Variations between countries in invasive cardiac procedures and outcomes in patients with suspected unstable angina or myocardial infarction without initial ST elevation. OASIS (Organisation to Assess Strategies for Ischaemic Syndromes) Registry Investigators. Lancet 352:507-514

3. Yui Y, Hirayama A, Nonogi H, Kimura K, Kodama K, Hosoda S, Kawai C (2007) Unstable angina and non-ST elevation acute coronary syndrome: epidemiology and current management in Japan (Japan Multicenter Investigation for Cardiovascular Disease-D (JMIC-D) Committee). Circ J 71:1335-1347

4. Nishigaki K, Yamazaki T, Fukunishi M, Tanihata S, Fujiwara H (2004) Assessment of acute myocardial infarction in Japan by the Japanese Coronary Intervention Study (JCIS) Group. Circ J 68:515-519

5. Roe MT, Chen AY, Mehta RH, Li Y, Brindis RG, Smith SC Jr, Rumsfeld JS, Gibler WB, Ohman EM, Peterson ED (2007) Influence of inpatient service specialty on care processes and outcomes for patients with non ST-segment elevation acute coronary syndromes. Circulation 116:1153-1161

6. Fox KA, Anderson FA Jr, Dabbous OH, Steg PG, Lopez-Sendon J, Van de Werf F, Budaj A, Gurfinkel EP, Goodman SG, Brieger D (2007) Intervention in acute coronary syndromes: do patients undergo intervention on the basis of their risk characteristics? The Global Registry of Acute Coronary Events (GRACE). Heart 93:177-182

7. Hasdai D, Behar S, Wallentin L, Danchin N, Gitt AK, Boersma E, Fioretti PM, Simoons ML, Battler A (2002) A prospective survey of the characteristics, treatments and outcomes of patients with acute coronary syndromes in Europe and the Mediterranean basin; the Euro Heart Survey of Acute Coronary Syndromes (Euro Heart Survey ACS). Eur Heart J 23:1190-1201

8. Nakamura M, Yamashita T, Yajima J, Oikawa Y, Ogasawara K, Sagara K, Kirigaya H, Koike A, Nagashima K, Ohtsuka T, Uejima T, Suzuki S, Sawada H, Aizawa T (2010) Clinical outcome after acute coronary syndrome in Japanese patients: an observational cohort study. J Cardiol 55:69-76

9. Suzuki S, Sagara K, Otsuka T, Matsuno S, Funada R, Uejima T, Oikawa Y, Koike A, Nagashima K, Kirigaya H, Yajima J, Sawada H, Aizawa T, Yamashita T (2012) Gender-specific relationship between serum uric acid level and atrial fibrillation prevalence. Circ J 76:607-611

10. Suzuki S, Yamashita T, Ohtsuka T, Sagara K, Uejima T, Oikawa Y, Yajima J, Koike A, Nagashima K, Kirigaya H, Ogasawara K, Sawada H, Aizawa T (2008) Prevalence and prognosis of patients with atrial fibrillation in Japan: a prospective cohort of Shinken Database 2004. Circ J 72:914-920

11. Matsuo S, Imai E, Horio M, Yasuda Y, Tomita K, Nitta K, Yamagata K, Tomino Y, Yokoyama H, Hishida A (2009) Revised equations for estimated GFR from serum creatinine in Japan. Am J Kidney Dis 53:982-992

12. Batchelor WB, Anstrom KJ, Muhlbaier LH, Grosswald R, Weintraub WS, O'Neill WW, Peterson ED (2000) Contemporary outcome trends in the elderly undergoing percutaneous coronary interventions: results in 7,472 octogenarians. National Cardiovascular Network Collaboration. J Am Coll Cardiol 36:723-730

13. Teplitsky I, Assali A, Golovchiner G, Shor N, Weiss A, Battler A, Kornowski R (2003) Acute and intermediate-term results of percutaneous coronary stenting in octogenarian patients. Int $\mathrm{J}$ Cardiovasc Intervent 5:195-199

14. Graham MM, Ghali WA, Faris PD, Galbraith PD, Norris CM, Knudtson ML (2002) Survival after coronary revascularization in the elderly. Circulation 105:2378-2384

15. De Gregorio J, Kobayashi Y, Albiero R, Reimers B, Di Mario C, Finci L, Colombo A (1998) Coronary artery stenting in the 
elderly: short-term outcome and long-term angiographic and clinical follow-up. J Am Coll Cardiol 32:577-583

16. Pfisterer M, Buser P, Osswald S, Allemann U, Amann W, Angehrn W, Eeckhout E, Erne P, Estlinbaum W, Kuster G, Moccetti T, Naegeli B, Rickenbacher P (2003) Outcome of elderly patients with chronic symptomatic coronary artery disease with an invasive vs optimized medical treatment strategy: oneyear results of the randomized TIME trial. JAMA 289:1117-1123

17. Bock JS, Gottlieb SS (2010) Cardiorenal syndrome: new perspectives. Circulation 121:2592-2600

18. Pfisterer M (2004) Long-term outcome in elderly patients with chronic angina managed invasively versus by optimized medical therapy: four-year follow-up of the randomized Trial of Invasive versus Medical therapy in Elderly patients (TIME). Circulation 110:1213-1218

19. Robertson RM, Wood AJ, Vaughn WK, Robertson D (1982) Exacerbation of vasotonic angina pectoris by propranolol. Circulation 65:281-285

20. Shlipak MG, Massie BM (2004) The clinical challenge of cardiorenal syndrome. Circulation 110:1514-1517

21. Yusuf S, Wittes J, Friedman L (1988) Overview of results of randomized clinical trials in heart disease I. Treatments following myocardial infarction. JAMA 260:2088-2093

22. Yusuf S, Peto R, Lewis J, Collins R, Sleight P (1985) Beta blockade during and after myocardial infarction: an overview of the randomized trials. Prog Cardiovasc Dis 27:335-371

23. Dargie HJ (2001) Effect of carvedilol on outcome after myocardial infarction in patients with left-ventricular dysfunction: the CAPRICORN randomised trial. Lancet 357:1385-1390

24. Yusuf S, Sleight P, Pogue J, Bosch J, Davies R, Dagenais G (2000) Effects of an angiotensin-converting-enzyme inhibitor, ramipril, on cardiovascular events in high-risk patients. The Heart Outcomes Prevention Evaluation Study Investigators. N Engl J Med 342:145-153
25. Fox KM (2003) Efficacy of perindopril in reduction of cardiovascular events among patients with stable coronary artery disease: randomised, double-blind, placebo-controlled, multicentre trial (the EUROPA study). Lancet 362:782-788

26. The Scandinavian Simvastatin Survival Study (4S) (1994) Randomised trial of cholesterol lowering in 4444 patients with coronary heart disease: the Scandinavian Simvastatin Survival Study (4S). Lancet 344:1383-9

27. The Long-Term Intervention with Pravastatin in Ischemic Disease (LIPID) Study Group (1998) Prevention of cardiovascular events and death with pravastatin in patients with coronary heart disease and a broad range of initial cholesterol levels. The LongTerm Intervention with Pravastatin in Ischemic Disease. N Engl J Med 339:1349-57

28. Ridker PM, Danielson E, Fonseca FA, Genest J, Gotto AM Jr, Kastelein JJ, Koenig W, Libby P, Lorenzatti AJ, MacFadyen JG, Nordestgaard BG, Shepherd J, Willerson JT, Glynn RJ (2008) Rosuvastatin to prevent vascular events in men and women with elevated C-reactive protein. N Engl J Med 359:2195-2207

29. Borden WB, Redberg RF, Mushlin AI, Dai D, Kaltenbach LA, Spertus JA (2011) Patterns and intensity of medical therapy in patients undergoing percutaneous coronary intervention. JAMA 305:1882-1889

30. Kimura T, Morimoto T, Furukawa Y, Nakagawa Y, Shizuta S, Ehara N, Taniguchi R, Doi T, Nishiyama K, Ozasa N, Saito N, Hoshino K, Mitsuoka H, Abe M, Toma M, Tamura T, Haruna Y, Imai Y, Teramukai S, Fukushima M, Kita T (2008) Long-term outcomes of coronary-artery bypass graft surgery versus percutaneous coronary intervention for multivessel coronary artery disease in the bare-metal stent era. Circulation 118:S199-209

31. Ramanathan KB, Weiman DS, Sacks J, Morrison DA, Sedlis S, Sethi G, Henderson WG (2005) Percutaneous intervention versus coronary bypass surgery for patients older than 70 years of age with high-risk unstable angina. Ann Thorac Surg 80:1340-1346 